\title{
Determination of User Preferences on Visual Landscape at Urban Context: Van/Edremit (Turkey) Example
}

\author{
Feran Aşur* \\ Van Yüzüncü Y1l University, Faculty of Architecture-Design, Department of Landscape Architecture, Van, Turkey
}

Received: 1 May 2021

Accepted: 12 July 2021

\begin{abstract}
In measuring the space quality, user preferences regarding the space are one of the important indicators. With the increasing urbanization phenomenon in Edremit district which has important cultural and natural assets in terms of greenness, the distinction between old and new settlements has become more visible. This study aims to determine the factors which increase preference in urban landscapes, user preferences and attitudes towards space, and to make suggestions for the improvement of urban landscapes. The main method of the study based on visual evaluation techniques is the visual questionnaire technique, which is applied with visuals and helps to determine the user's perception of the space. As a result of the study, it was revealed that places with coherence which is among the information processing variables, were liked more by the users. Natural designs seem complex, according to the conclusion that coherence increases with the signs of human existence, it has been revealed that in order to increase the coherence in the field with planting design, balance should be achieved, but naturalness should be avoided. According to the result for sustainable development, the hypothesis of urban designs supported by the green texture is more admirable, and is a confirmed improvement of urban landscapes.
\end{abstract}

Keywords: visual landscape preferences, urban landscape, landscape design, sustainble development

\section{Introduction}

Rapid urbanization in the recent century causes psychological isolation and future anxiety on the people of the city, as well as environmental problems in natural areas, urban centers and rural areas. With the Covid 19 pandemic that has affected the whole world

*e-mail: feranekasur@gmail.com since the beginning of 2020, green areas in the urban environment of people were mentioned a lot. According to Eşbah and Eşbah [1] the classical healthy city model focuses on the act of creating a more livable and healthier environment, which is the main purpose of the discipline of Landscape Architecture and other planning and design disciplines. Preserving healthy environments encourages connecting and supporting, requires interdisciplinary and inter sectoral collaborations. According to Chen et al., [2] landscape aesthetics is also closely related to stress relief mental and physical 
benefits $[3,4]$. The reason is that plants, as alive and living beings that tell people the seasons change, day's hours and have different spatial expressions than classical inanimate design objects. Plants are a design material with different dimensions because they make you feel vitality and health [5-9]. Landscape design can be defined as an effort to achieve the harmonious use of structural and plant elements in outdoor spaces. Environmental assessment process is defined as "the process of making contain choices and making certain as a result of the perception of environmental qualities" [10-13].

Among the 5 evolutionary-based theories developed to understand landscape aesthetics, the theory of Prospect-refuge, first emerged by Appleton [14] as an explanation for human preferences regarding the environment. The developed theory moves from the role of ancient humans to be both predators and prey in the wild [15]. Dronova [16] and Tveit et al. [15] in their works they state that Appleton argues the existence of both prospect and refuge areas in a landscape provided an advantage for primitive human populations. Therefore, according to this theory, the landscape preferences of today's people reflect this historical situation [15]. User preferences regarding the space are one of the important indicators in measuring the quality of the space. For the evidence-based design developed in recent years, user input is required. Planting design is an important design discipline in the greenery of daily used areas in the city. Smardon [17] states that plant in all forms contributes to visual development, trees constantly break up building facades and add recognizability to the place, bushes soften the image by blocking the places where the buildings meet with the soil, grass and groundcovers help defining of the ground slab boundaries. However, there are urban planting trees and medium-sized shrubs in the traditional image of cities. Therefore, the existence of plant and their change with the seasons are very important for urban environments [18]. One of the main challenges when analyzing landscape change is the lack of functional landscape indicators for visual quality. There is a strong conceptual basis that drives research in the context of quantitative indicators for many environmental issues such as pollution, soil erosion, product quality, availability and biodiversity. However, this conceptual framework for the visual aspect of the landscape is weak and progress very slowly in terms of visual indicator development. Therefore, it is difficult to compare different landscapes or the same landscape over time. Landscape patterns affect a person's perception of ordinary environments in his/her daily life [19-21]. In addition, landscape aesthetics theories state that landscape patterns can be used to predict landscape preferences, define visual characters with nine key concepts, and associate quantitative pattern analysis with qualitative landscape preferences. These nine key concepts are: stewardship, coherence, disturbance, historicity, visual scale, imageability, complexity, naturalness and ephemera
[22]. In information processing theory which is one of the landscape preference theories, Kaplan et al., [23] by questioning the results of various studies, looking at many landscape scenes in light of preference scores and working on how the environment transmits information, they found a helpful approach to the design and management of natural environments. According to this approach, preferred environments have four important features. These four important features are: coherence, complexity, legibility and mysteriousness.

Van/Edremit county, which has important cultural and natural landscapes, has become more evident in the green texture between the new settlement and the old settlement with the increasing urbanization phenomenon in the recent period. For sustainable development, the hypotheses put forward in this study are:

- Urban residential areas with green texture are more appreciated in terms of visual landscaping,

- Areas that preserve their naturalness in urban spaces should be preferred more.

In this context, according to Kaplan et al.'s [23] approach, the four important visual indicators that are effective on landscape preferences; coherence, complexity, legibility and mysteriousness, were determined in the urban spaces of Edremit district.

This study aims to determine the factors that increase user preferences in urban landscapes, user preferences, attitudes of different social groups towards space and to make suggestions for the improvement of the urban landscape. With the regression models created in the study, determination visual preferences related to the urban area by using formal aesthetic variables which are significant predictors, will be widespread and create contribution on country base. The data obtained will contribute to professional disciplines such as landscape architects, urban planners and architects in studies to be carried out on the basis of sustainable urban landscape planning and design. Local administrators, municipalities and other city stakeholders will have the ability to predict new urban developments within the framework of the findings from this study.

\section{Experimental}

\section{Material and Method}

The study was carried out in Edremit district in the province of Van in Eastern Anatolia Region (Eastern Turkey). The location of the district follows the coast line, and the length of the district center is $24 \mathrm{~km}$ and its width varies between $16-18 \mathrm{~km}$. In the study, the natural and built landscapes of various old and new residential areas and their immediate surroundings in the district are discussed (Fig. 1). In addition, census data related to the area, literature related to landscape and environmental aesthetics, photographs taken in the area, survey data constitute the main materials of the research. 


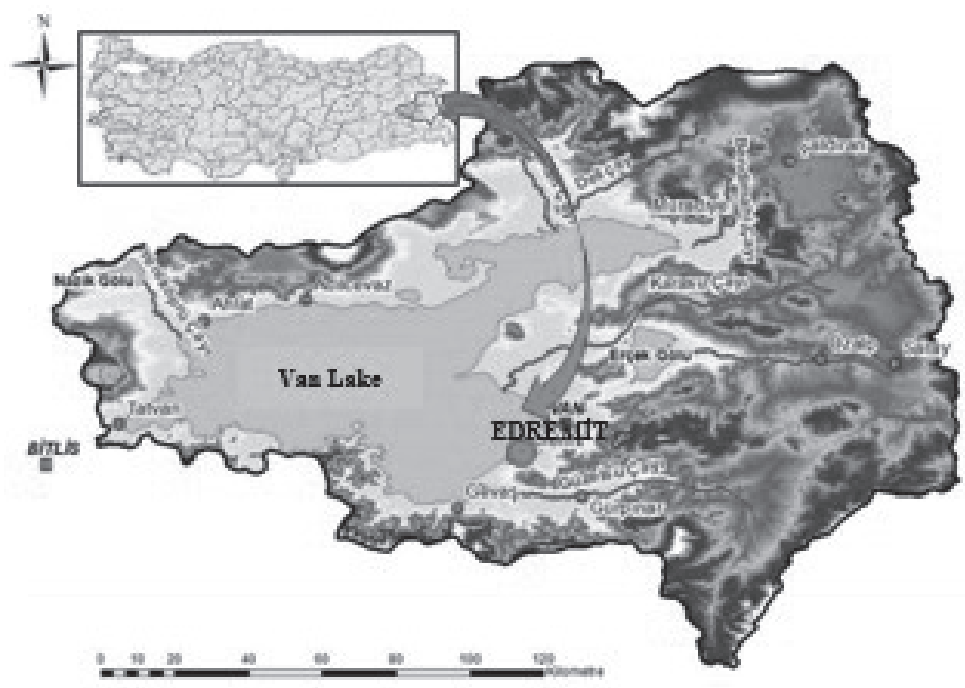

Fig. 1. The location of the study area.

This study was carried out with visual landscape evaluation techniques. The main method of the research is the visual questionnaire technique, which is applied with visuals and helps to determine the user's perception of the space. In this context, based on information processing theory, four features that are effective in environmental preference; In terms of coherence, complexity, legibility and mysteriousness [23], the visual preferences of the users in the urban spaces of Edremit district were determined. According to the results of the address-based census, the population of Edremit district in 2017 was 124,375 people. The simple random sampling method was chosen and according to the sampling calculation for $\mathrm{p}=0.5 \mathrm{q}=0.5$ with \pm 0.05 sampling error, it was predicted that a minimum of 400 questionnaires would represent the district within the specified deficiencies. In order to apply the preferences questionnaire in terms of urban landscapes, which is used to determine the perceptions of the users towards the space, first of all, expert opinion was sought in landscape selection. One-way Anova, correlation and regression tests were applied on the data collected in the questionnaire. With the created regression models, formal aesthetic variables, which are significant predictors of preferences regarding urban area, were determined. In the research, the method of determining the landscape preference with the help of photo-questionnaire, which was widely used before [24-32], was used. The main reason for using the photosurvey application is that it provides a fast, reliable and environment where participants can express their opinions more easily. The landscapes which in different proportions and in the urban and urban green areas of the district were framed and photographs were taken. The 1012 obtained photographs were classified according to their content. 258 photographs were selected for the sampling survey as a result of the selection depended on photographs' content.
The sampling questionnaire was sent to the experts in five parts on the internet. 5 experts were asked to score 5 items under the titles of liking, coherence, complexity, legibility and mysteriousness for each photograph in the context of formal aesthetic variables on a 5-likert scale. When the experts completed the scoring, the data matrix obtained by taking the average of the points given was encoded into the "spss" program and hierarchical cluster analysis was performed. Dendrograms (clusters) according to the pores were revealed by this analysis. There are 17 clusters with more than 3 stems (SAP) with $10 \%$ similarity in this context, the analysis outputs were printed, clusters were determined and 3 most liked, least admired and moderately admired photographs were selected for the survey.

\section{Results and Discussion}

Among the 400 participants in the survey, $66 \%$ are women and $33 \%$ are men. When the age distribution of the participants is examined, it is seen that $37 \%$ of them are between the ages of 15-18, the majority of them are between the ages of $19-29$, and $14.0 \%$ are between the ages of 30-49. Participants between the ages of $50-65$ make up $8.3 \%$, while $2.5 \%$ of the participants are 65 and over. $2.5 \%$ of the respondents have education at the primary school level, $33.5 \%$ have at the undergraduate level, $7 \%$ have at the master's level, and $4 \%$ have a doctorate level. $0.3 \%$ of the participants are workers, $3.5 \%$ are working in the private sector, $1.3 \%$ are self-employed, $9.8 \%$ are civil servants, $0.8 \%$ are tradesmen, $3.3 \%$ retired, $71.3 \%$ students, $4.3 \%$ housewives, $0.5 \%$ unemployed, 18 are in the other category. When the monthly incomes of the participants were considered, it is observed that 250 people have the minimum wage and below and 38 people have an income of about 550 Dollars and above. 
Table 1. Relationship between information processing theory variables and public taste.

\begin{tabular}{|c|c|c|c|c|c|}
\hline \multicolumn{6}{|c|}{ Correlation } \\
\hline & & Coherence & Complexity & Legibility & Mysteriousness \\
\hline \multirow{2}{*}{ Popular Likes } & Correlation Value & $.815^{* *}$ & .131 & $.723^{* *}$ & $.610^{* *}$ \\
\hline & $P$ value & .000 & .360 & .000 & .000 \\
\hline \multirow{2}{*}{ Coherence } & Correlation Value & & .080 & $.812^{* *}$ & $.692^{* *}$ \\
\hline & $P$ value & & .578 & .000 & .000 \\
\hline \multirow{2}{*}{ Complexity } & Correlation Value & & & .103 & .150 \\
\hline & $P$ value & & & .470 & .294 \\
\hline \multirow{2}{*}{ Legibility } & Correlation Value & & & & $.518^{* *}$ \\
\hline & $P$ value & & & & .000 \\
\hline
\end{tabular}

Questioning the Relationship Between Information Processing Theory Variables and Public Appreciation

After the implementation of the public survey, the averages of the answers given were taken and these results were associated with the variables in the survey of the previous expert group's results on the photographic basis. In this context, it seems useful to look at the correlation relations between photographic user preferences and information processing theory variables. It is seen in Table 1 that the highest correlation of the public survey is with the coherence variable. Accordingly, coherence is in a highlevel relationship with user liking, such as $r=0.815$ $(\mathrm{P}<0.001)$. By looking at the sign, it is seen that the correlation coefficient has a positive value. This means that with the increase of the perceived coherence in the photograph, the liking of the user also increases. Another relationship was determined between legibility and public preferences $(r=0.723 p<0.001)$. Finally, it is seen in the table that there is a moderate relationship between public preferences and mysteriousness $(\mathrm{r}=0.610 \mathrm{p}<0.001)$. Here, too, a positive relationship is visible.

\section{Determining the Information Processing Variables that Affect Users' Appreciation Scores for Photographs}

At this stage of the study, the average of the appreciation points of the users for the photographs was taken as the dependent variable, the average of the answers given by 5 different experts to the information processing variables (Coherence, Legibility, Mysteriousness, Complexity variables) was defined as an independent variable and a stepwise regression analysis was applied. According to the results of the analysis in Table 2, it is seen that the regression analysis is completed in one step and the coherence variable is an important predictor in terms of its contribution to the variance regarding the preference of the users. In the first and only phase of the analysis, the coherence variable was taken, which explains $66.5 \%$ of users" "liking". Considering the sign of the regression coefficient, it is seen that the relationship between the coherence variable and the liking of the users is positive. This single variable explains $66.5 \%$ of the total variance of users' likes.

Accordingly, coherence, as an only information processing variable, is seen as a significant factor in the regression model. In other words, the information processing theory variable that affects the users' preference of the urban spaces in Edremit the most is coherence. As can be understood from here, information processing theory can explain the aesthetic preferences of Edremit users about urban spaces. This may be an indication of the prevalence of information processing theory among evolutionary psychological aesthetic theories. As a result of this analysis, the preferences of the users can be reached with the following formula: User Preferences $=-0.274$ (Fixed) + 0.942 (Consistent).

\section{Users' Prefrence Points For Photos}

In the study, as a result of the visual impact evaluations of the landscapes, Photograph A is the most liked visual by the users, getting an average score of 4.24. Considered rich in visual diversity, this landscape has a high coherence score. Photo B includes a dense plant with a broad perspective with an average of 4.16. It is followed by Photograph $\mathrm{C}$, which also includes a dense plant with an average of 4.12. In the fourth place, the favorite landscape was Photograph D with an average of 4.00 , which has an image close to nature and dense plant material. In the fifth place is Photograph $\mathrm{E}$, which has a rich visual variety with an average of 3.99. The images that users like the most are listed in Table 3. 
Table 2. Progressive multiple regression results regarding of the prediction the preference of the users.

\begin{tabular}{|c|c|c|c|c|c|c|c|}
\hline Information Processing Variable & $\mathrm{R}$ & $\Delta \mathrm{R}^{2}$ & $\mathrm{~B}$ & $\mathrm{SH}_{\beta}$ & $\beta$ & $\mathrm{T}$ & $\mathrm{P}$ \\
\hline Coherence & 0.815 & 0.665 & 0.942 & 0.096 & 0.815 & 9.856 & 0.000 \\
\hline Constant & - & - & -0.274 & 0.330 & - & -0.831 & 0.410 \\
\hline
\end{tabular}

Total: $\mathrm{R}^{2}=0.665 \quad \mathrm{~F}(1.49)=97.141 \quad \mathrm{P}=0.000$

In terms of users' Preferences, the last five images that got the least score among 50 photos are given in Table 4. Accordingly, from the visuals used in the study. A landscape that lacks plant and includes humanmade negative elements and does not have positive visual diversity, Photograph $\mathrm{F}$ is the least liked visual with an average score of 1.51 as a result of the users' scoring. The following photograph $\mathrm{G}$ without plant, with an average of 1.65 , with a dirt road and a view of a rubble stone wall. This is followed by Photo $\mathrm{H}$, which contains a view of an urban space with an average of 1.76 and topographical difference, with a bare land with

Table 3. Five images that ranked among the top five according to users' appreciation scores.

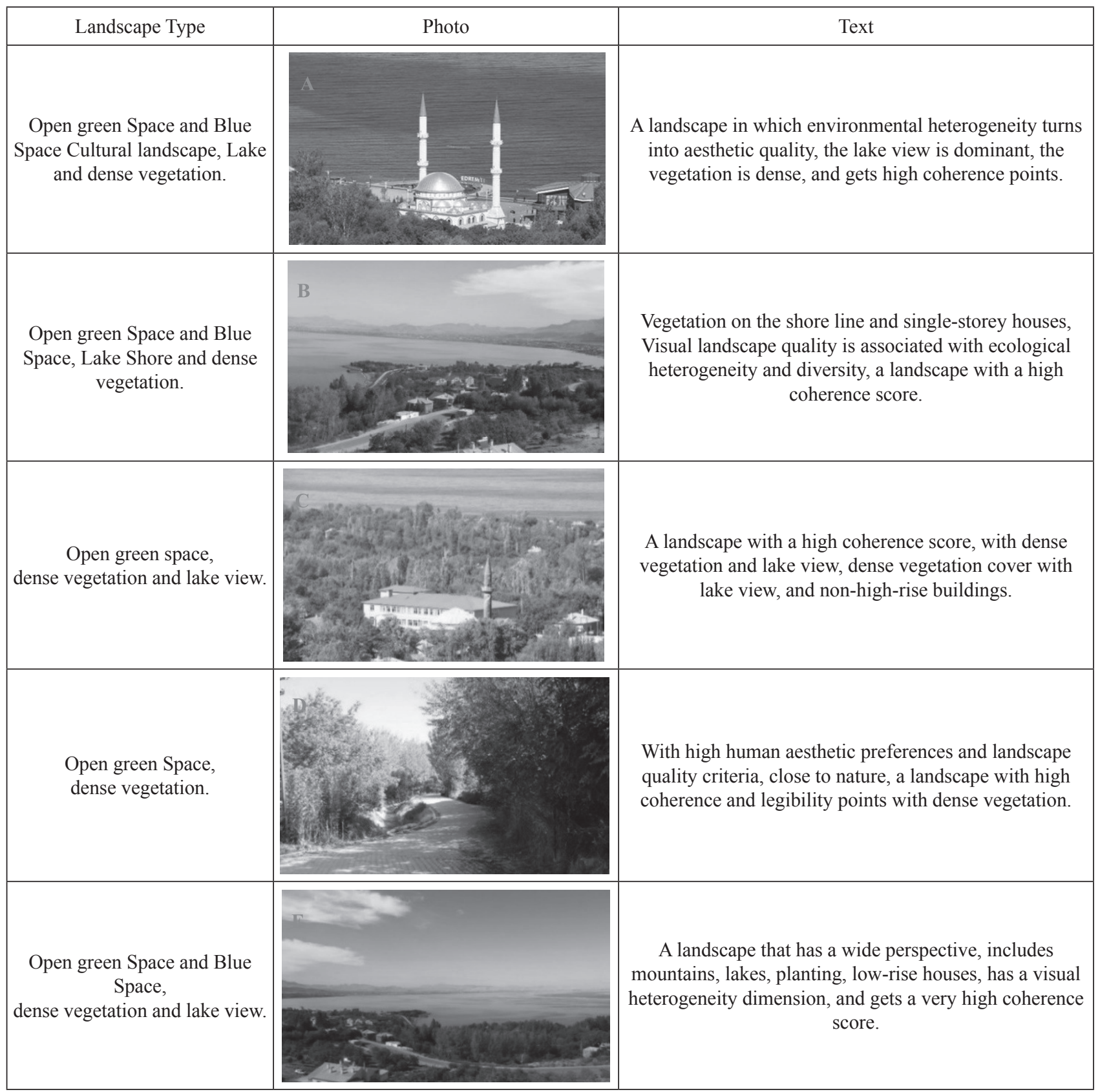


Table 4. The visual in the last five places with low visual impact values according to the users' appreciation scores

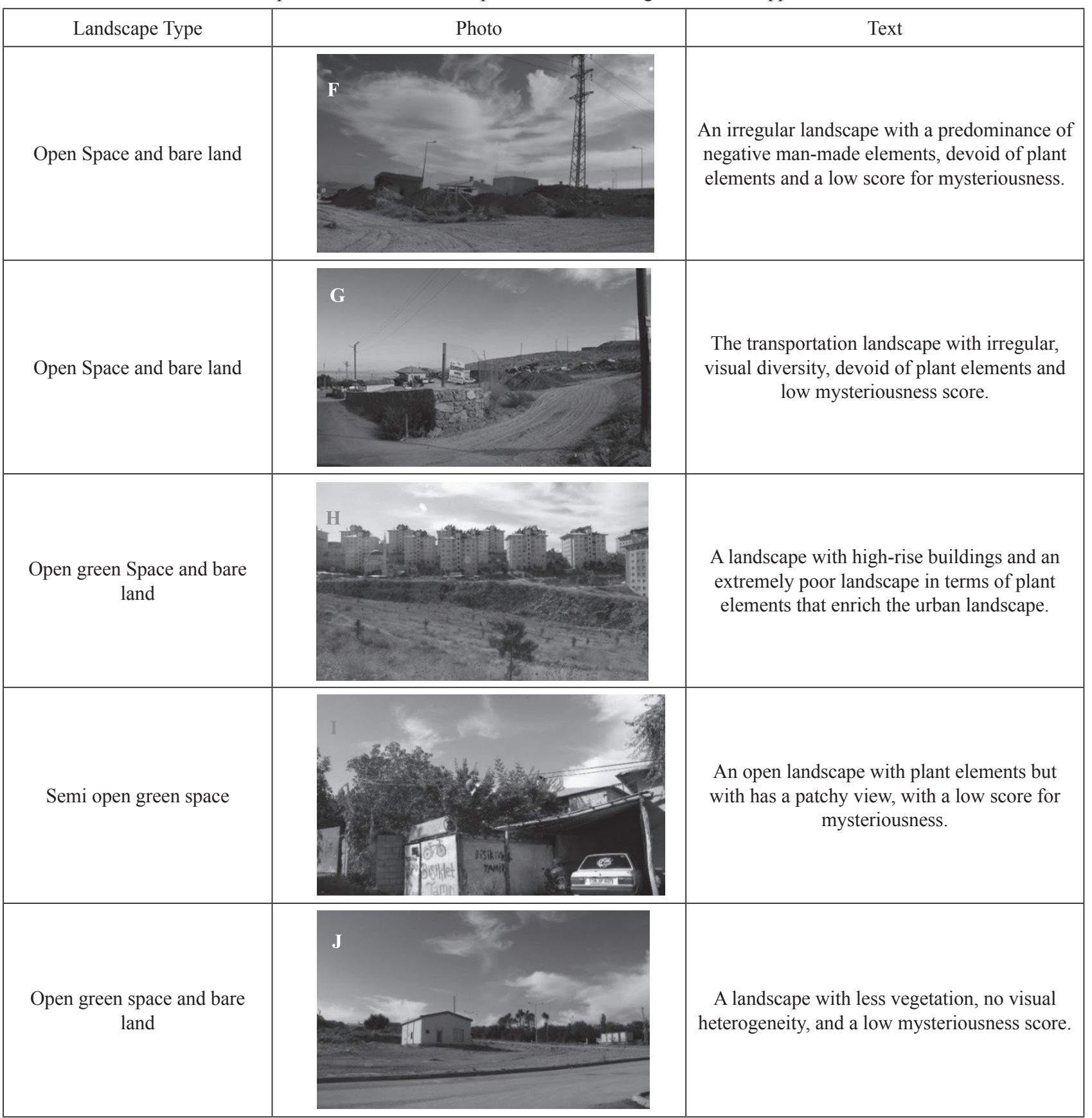

weak plant behind it. It is followed by visual Photo I with graffiti with a patchy garage with an average of 1.85. With an average of 1.85 , the image showing the view of the single hut in an empty area, with an average of 1.8525 , takes the fifth place among the less popular visuals.

\section{Conclusions}

As a result of the observations made, it has been revealed that the urbanization effect has increased in recent years in Van/Edremit district, which has important cultural and natural landscape assets. Therefore, the distinction between the old and new settlements in terms of green texture has become more evident. Since the determination of user preferences for visual landscapes is one of the important indicators in measuring the quality of space in urban areas, the visual landscape preferences of the users in the Van/Edremit example are presented in this study. Within the framework of the findings obtained at the end of this study. It has been revealed that there is a positive relationship between the variables of information processing theory and user preferences. The correlation test performed shows that there is a significant positive relationship between three variables. These variables are coherence, legibility, 
and mysteriousness. Interestingly, complexity did not appear to be a significant variable. This may be because of the spaces shown in the photo have a more modest and simple composition. The fact that the users less appreciate the natural but complex landscapes in urban spaces does not confirm the hypothesis that "areas that preserve their naturalness in urban spaces are preferred more". Therefore, it is a reality to include regular and uncomplicated designs in the designs made in urban spaces. According to the user, Edremit has a mysteriousness with memorable components that help orient and distinguish the landscape. It also has an inviting landscape that makes users want to explore this place. However, as shown in the performed regression analysis, coherence emerged as the most significant and predictive variable. Places that have coherence among the information processing variables are more liked by the users. The reason for this may be that photographs with high coherence among monolithic designs are more likely to attract public attention. Based on the results, the coherence of Edremit district according to the user; It has the characteristic of being organized as a regular, defined area. According to the user, Edremit: has features that can easily comprehend the existence of a few distinct regions or areas that facilitate understanding or making sense of space. When the table which the photographs are ranked according to average scores is examined, it is immediately striking that the coherence in the first five photographs is high. The high amount of green texture in these five photos is another important indicator. In this respect, green parts seem important in ensuring the coherence of space in urban development. In this context, the hypothesis that "urban settlements with green texture are more admired in terms of visual landscape" is confirmed in Van / Edremit district. In order to increase the coherence in the field with planting design, balance should be provided, but naturalness that creates complexity should be avoided. In this context, the natural areas in the area seem very complex, the coherence increases more with the signs of human existence. In addition, the fact that four of these five photographs dominate the view from a high place is another important finding. Unfortunately, the "Prospect Refuge" theory was not tested in this study. This is one of the limitations of the study. In future studies, it is recommended to test the prospect refuge theory if the study has dominant landscape spaces available to test. There are many such places with a panoramic view of Van Lake in the study area. It can be argued that urban designs supported with green texture will be more appreciated in these spaces. [33-39] mentioned that plant has an active role in the sustainability of urban life, and that they have aesthetic, ecological, socio-cultural, psychological, hygienic and functional comprehensive benefits. In parallel with this, the Edremit example will increase the quality of life in the urban space, based on the results of the analyzes made in the study. The importance of plant and plant compositions can be emphasized in solving visual problems by revealing the factors that increase the preference in urban landscaping. For sustainable development, public spaces that are arranged in accordance with the climatic conditions and with the right planting design will encourage the city dwellers to spend more time outdoors and make it possible to create more interesting urban spaces in terms of visual landscape. In the light of these results, it appears that these concepts should also be taken into account in the future urban designs in line with the environmental preferences of the users. The results of the study can be a useful source of information for landscape architects and city planners, by determining user preferences regarding urban landscapes.

\section{Acknowledgments}

This Study (Project code: FBA-2018-7272) was supported by the Scientific Research Projects Coordination Unit of the Van Yüzüncü Yil University.

\section{Conflict of Interest}

The authors declare no conflict of interest.

\section{References}

1. EŞBAH H.T., EŞBAH H. Healthy Cities and Pandemic: Thoughts About Covid19 Pandemic. Journal of Landscape - Education, Science, Culture and Art, 2 (2), 57, 2020.

2. CHEN Z., XU B., DEVEREUX B. Assessing public aesthetic preferences towards some urban landscape patterns: the case study of two different geographic groups, Environmental Monit Assessment 188 (4), 1, 2016.

3. ULRICH R.S., SIMONS R.F., LOSITO B.D., FIORITO E., MILES M.A., ZELSON M. Stress recovery during exposure to natural and urban environments. Journal of Environmental Psychology, 11, 201, 1991.

4. ODE A.K., FRY G.L.A. Visual aspects in urban woodland management. Urban Forestry Urban Greening, 1, 15, 2002.

5. MISGAV A. Visual Preference of the Public for Vegetation Groups in Israel. Landscape and Urban Planning, 48 (34), 143, 2000.

6. KORKUT A., KIPER T., TOPAL T.Ü. Ecological Approaches in Urban Landscape Design. Artium, 5 (1), 14, 2017.

7. FRANCH-PARDO I., CANCER-POMAR L., NAPOLETANO B.M. Visibility analysis and landscape evaluation in Martin river cultural park (Aragon, Spain) integrating biophysical and visual units. Journal of Maps, 13 (2), 415, 2017.

8. OKTAY H.E. In the Assessment of Palnting Landscape Designs: The Case Study of Antalya Konyaaltı Region. PhD Thesis. Department of Landscape Architecture, 226 Antalya. 2017.

9. ASUR F., DENİZ SEVIMLİ S., YAZİCİ K. Visual Preferences Assessment of Landscape Character Types Using Data Mining Methods (Apriori Algorithm): The Case of Altınsaç and Inkoy (Van/Turkey). Journal of Agricultural Science and Technology, 22 (1), 247, 2020. 
10. GAO Y., MA L., LIU J., ZHUANG Z., HUANG Q., LI M. Constructing ecological networks based on habitat quality assessment: a case study of Changzhou, China. Scientific reports, 7 (1), 1, 2017.

11. GÓRKA A. Visual Capacity Assessment of the Open Landscape in Terms of Protection and Shaping: Case Study of a Village in Poland. Sustainability, 12 (16), 6319, 2020.

12. KÜLEKCİ E.A., IRMAK M.A. Efficiency of Equipment Elements Used in Urban Parks from Aesthetical and Functional Perspectives; In the Sample of Erzurum City Journal of the Institute of Science and Technology of Igdir University 9 (2), 1144, 2019.

13. HAMMAlOĞLU A.G., AKTEN M. Urban Aesthetic Research in Muratpasa District, Süleyman Demirel University, Journal of Natural and Applied Sciences, 24 (3), 647, 2020.

14. APPLETON J. Landscape evaluation: the theoretical vacuum. Transactions of the Institute of British Geographers, 120, 1975.

15. TVEIT M.S., SANG A.O., HAGERHALL C.M. Visual Landscape Assessment and Landscape Perception. Chapter 4: Natural Beauty, In: L. Steg, A. E. Van der Berg, and J. M. De Groot (Editors) Environmental Psychology, Nobel Publishing House, Istanbul, Turkey, 37, 2015.

16. DRONOVA I. Environmental Heterogeneity as a Bridge between Ecosystem Service and Visual Quality Objectives in Management, Planning and Design. Landscape Urban Plan. 163, 90, 2017.

17. SMARDON R. Perception and aesthetics of the urban environment: review of the role of vegetation. Landscape Urban Plan. 15, 85, 1988.

18. TODOROVA A., ASAKAWA S., AIKOH T. Preferences for and attitudes towards street flowers and trees in Sapporo, Japan, Landscape and Urban Planning 69, 403, 2004.

19. ALABI M.O., ORIOLA E.O. Analysis of image differences of roadside corridor and landscape preference in an emerging city in Nigeria. Ethiopian Journal of Environmental Studies and Management, 10 (2), 192, 2017.

20. ZHAO J., LUO P., WANG R., CAI Y. Correlations between aesthetic preferences of river and landscape characters. J. Environ. Eng. Landscape Manage, 21 (2), 123, 2013.

21. WANG R., ZIO J., LIU Z. Consensus in visual preferences: The effects of aesthetic quality and landscape types. Urban Forestry \& Urban Greening, 20 (1), 210, 2016.

22. TVEIT M., ODE $A^{\circ}$., FRY G. Key Concepts in a Framework for Analyzing Visual Landscape Character, Landscape Research, 31 (3), 229, 2006.

23. KAPLAN R., KAPLAN S. The experience of Nature: a psychological Perspective. ABD Ann Arbor Michigan: Ulrich's Bookstore, 1989.

24. DANIEL T.C., BOSTER R.S. Measuring Landscape Esthetics: The Scenic Beauty Estimation Method. Usda Forest Service Research Paper, Rm-167, Rocky Mountain Forest and Range Experiment Station, Fort Collins, Co. 1976.

25. SHABANI G., SOUZANCHI K., JAVANMARDI M.H. Identifying the Components Affecting Visual Perception of the Spaces of Mountain Resorts (Case Study: Kolakchal Axis). MANZAR, the Scientific Journal of landscape, 12 (53), 40, 2020.

26. CLAY G.R., SMIDT R.K. Assessing the validity and reliability of descriptor variables used in scenic highway analysis. Landscape and Urban Planning, 66 (4), 239, 2004.

27. ARRIAZA M., CANAS-ORTEGA J.F., CANASMADUENOA JA., RUIZ-AVILES P. Assessing the visual quality of rural landscapes. Landscape and Urban Planning, 69, 115, 2004.

28. OŤAHEL' J., IRA V., HLAVATÁ Z., PAZÚR R. Visibility and perception analysis of city monuments: The case of Bratislava city centre (Slovakia). Moravian Geographical Reports, 26 (1), 55, 2018.

29. BEVK T., MARTINEZ N.M., BRERETON P., LALOŠEVI M., PERI M. Iterative digital photo-based assessment for rural landscape perception: A small experiment from County Wicklow, Ireland. Journal of Digital Landscape Architecture, 2, 18, 2017.

30. BULUT Z., SEZEN I., KARAHAN F. Determination of spring visual ceremonies of urban fruit trees and shrubs: A case study from Erzurum, Turkey. Journal of Food, Agriculture \& Environment, 8 (1), 289, 2010.

31. YANRU H., MASOUDI M., CHADALA A. OLSZEWSKA-GUIZZO A. Visual Quality Assessment of Urban Scenes with the Contemplative Landscape Model: Evidence from a Compact City Downtown Core. Remote Sensing, 12 (21), 3517, 2020.

32. SEZEN I., KÜLEKÇI E.A., KELEŞ B. Visual Quality Analysis of Urban Roadside Trees for Autumn Color Effects: The Case of Erzurum City. Urban Academy, 12 (4), 739, 2019.

33. KONIJNENDIJK C., SAYAKA S., RANDRUP T.B., SCHIPPERIJN J. "Urban and Peri - urban Forestry in a Development Contex - Strategy and implementation", Journal of Arboriculture, 30 (5), 269, 2004.

34. DİRIK H., ATA C. Planning, technical principals, concept and benefits of the urban forestry. Istanbul University Faculty of Forestry Journal, Series B, 55 (1), 1, 2005.

35. TANDOĞAN O., ŞIŞMAN E.E. Public Open Space Design and Plant Design for Liveable Winter Cities. Megaron, 13 (2), 334, 2018.

36. ASUR F. An Evaluation of Visual Landscape Quality of Coastal Settlements: A Case Study of Coastal Areas; In the Van Lake Basin (Turkey), Applied Ecology and Environmental Research, 17 (2), 1849, 2019.

37. DU H., JIANG H., SONG X., ZHAN D., BAO Z. Assessing the visual aesthetic quality of vegetation landscape in urban green space from a visitor's perspective. Journal of Urban Planning and Development, 142 (3), 04016007. 2016.

38. WANG R., ZHAO J. Demographic groups' differences in visual preference for vegetated landscapes in urban green space. Sustainable cities and society, 28, 350, 2017.

39. SANTÉ I., TUBÍO J.M., MIRANDA D. Public participation in defining landscape planning scenarios and landscape quality objectives (LQO): Landscape Guidelines for Galicia (NW Spain) case study. Land Use Policy, 94, 104559, 2020 